\title{
CONGENITAL HEART DISEASE ASSOCIATED WITH SUBDIAPHRAGMATIC LATERAL HETEROTAXY
}

\author{
BY \\ JOHN THOMSON \\ From the Department of Child Life and Health, University of Edinburgh
}

Received July 25, 1949

Since congenital heart disease associated with subdiaphragmatic lateral heterotaxy is seldom reported, it is thought desirable to record the following two cases.

Case 1. W. J. This full-time male child was born spontaneously on August 12, 1947. It was a first pregnancy and the parents were unrelated. The birth weight was $6 \mathrm{lb}$. 9 oz. and when the child left hospital on the ninth day he appeared to be in good condition and weighed $6 \mathrm{lb} .11 \mathrm{oz}$. When three months old he was referred to the author as a possible case of congenital heart disease.

There was a history of frequent cough and circumoral cyanosis. Præcordial pulsation was apparent and a forceful heart beat was palpable in the fifth, sixth, and seventh left intercostal spaces as far out as the anterior axillary line. There was a harsh systolic murmur of maximum intensity in the same area. Radiological examination disclosed a grossly abnormal cardiac outline suggestive of imperfect intracardial septa. There was also disclosed a subdiaphragmatic lateral heterotaxy.

Though physical growth was a little retarded, his general development was satisfactory. At a year old there were six teeth erupted, he could walk but needed to hold on, and speech had begun. The features were somewhat florid. The weight was just over $17 \mathrm{lb}$. At eighteen months he could walk well, put two words together, was active and showed no undue signs of breathlessness. He always wanted to go to bed about six in the evening and slept soundly till seven the following morning. There was no clubbing of the fingers but the florid appearance was more pronounced. The weight was $22 \mathrm{lb}$. While radiological examination was being repeated at this time, barium was given. The œsophagus was to the right of a left aortic arch. There appeared to be gross enlargement of the right ventricle (Fig. 1).

The following electrocardiogram report was also obtained. "The heart rate is high, but fairly regular at approximately 140 a minute. The P waves are deeply inverted in lead I, shallow in lead II, upright in lead III. There is marked right axis deviation. The T waves are flat in lead I, upright in leads II and III. In the chest leads there are moderate R waves in V1 to V3 with deeper $\mathrm{S}$. $\mathrm{S}$ is slurred in V1 and V2, of large amplitude in lead V3. T waves are high, upright and over $20 \mathrm{~mm}$. in V2. In V4 to V6 there are short $R$ and deep $S$ waves. $T$ is upright in V4, diphasic in V5, inverted in V6. Leads from the right chest, corresponding to V3, show R and S of nearly equal amplitude. $T$ is upright. The. lead from the right midclavicular line shows moderate $R$ with short $\mathbf{S}$. Leads from the anterior axillary and mid-axillary line on the right side show short $\mathbf{R}$ as predominant and sole initial deflection respectively. The leads from the right chest are of the type seen in a normal subject in leads from corresponding points on the left chest. Taken in conjunction with the appearance of standard lead I, these leads may be taken as highly suggestive of a true dextrocardia." (Fig. 2.) This is a most unusual electrocardiogram, as the heart seemed clinically and radiologically to be on the left. 


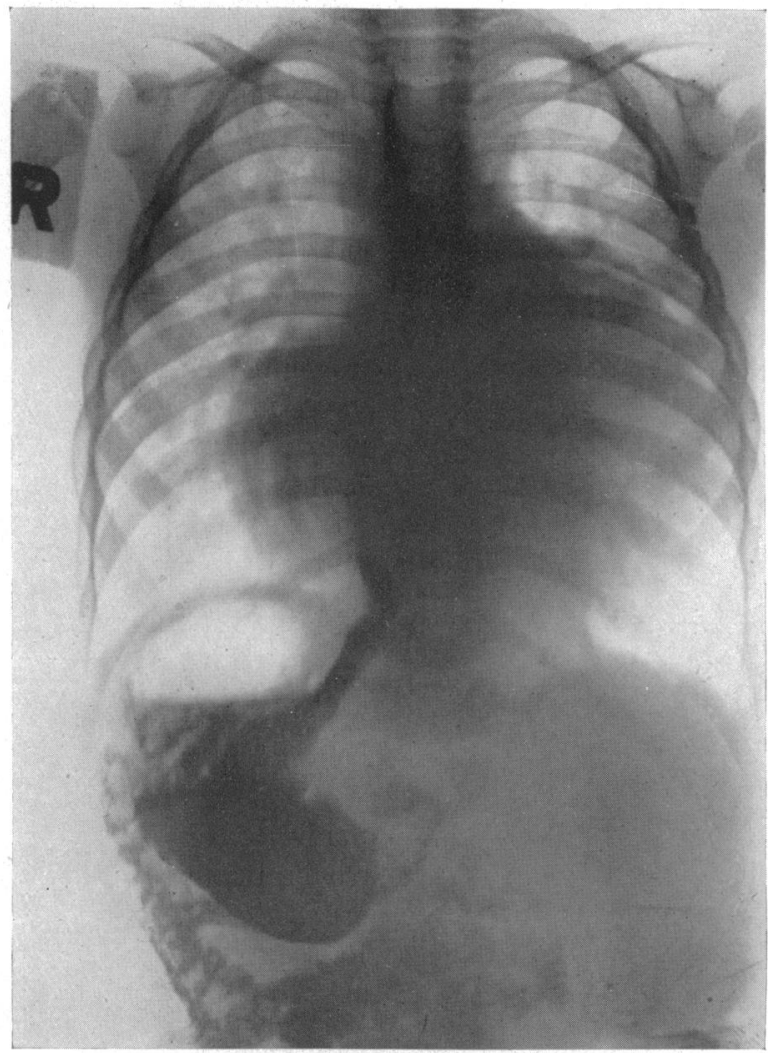

Fig. 1.-Case 1. Aged 18 months. Note the difference in the levels of the diaphragm on the two sides.

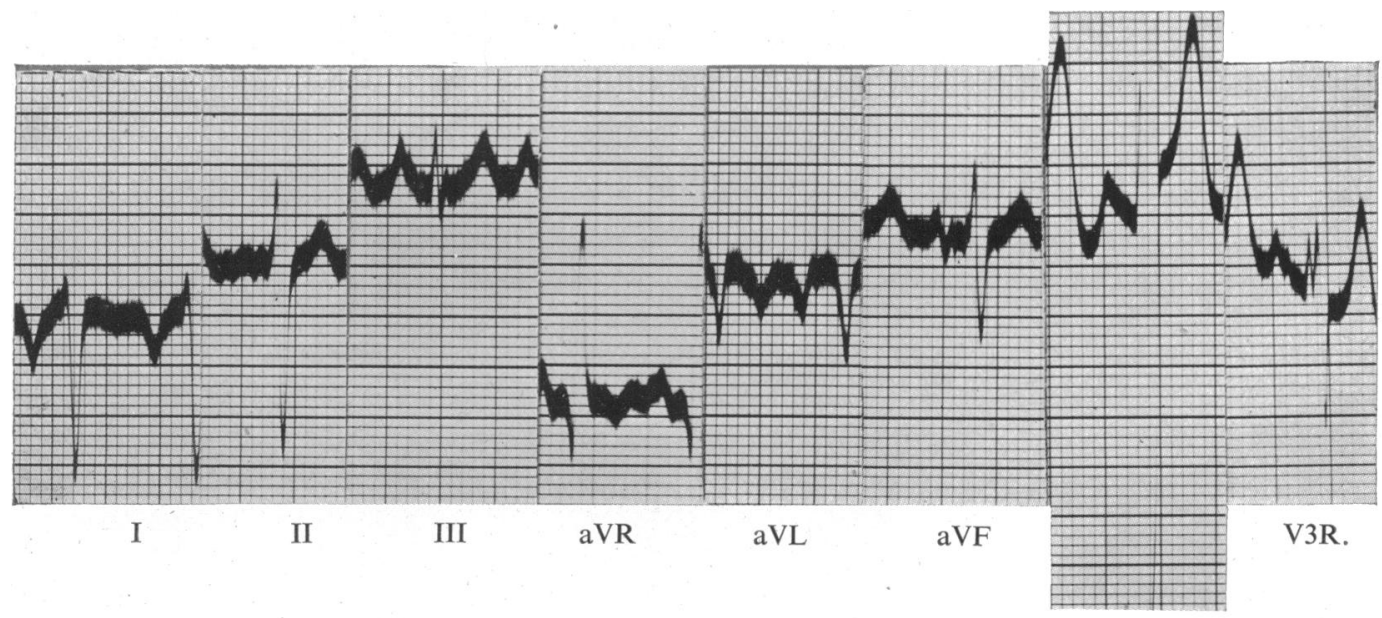

FIG. 2.-Electrocardiogram of Case 1. 
Both parents have been examined radiologically and found to be normal. There is no history of congenital malformation on either line of descent.

Case 2. C. I. This girl came to my notice when, at the age of six years, she formed one of a group of prematurely born children whose physical and mental progress was under review. She was born of unrelated parents on March 24, 1943. It was a fourth pregnancy. During the pregnancy signs of secondary syphilis became apparent and although active anti-syphilitic treatment was instituted, the patient being in hospital for the purpose, the infant was born after only two weeks treatment. At the time of delivery the period of gestation was calculated as 38 weeks. The birth weight of the infant was $4 \mathrm{lb} .8 \mathrm{oz}$. She was breast fed and made good progress, being discharged on the fifteenth day when she weighed $4 \mathrm{lb} .9 \mathrm{oz}$. Anti-syphilitic treatment was carried out and the Wassermann reaction was negative at 8 months, doubtfully positive at 15 months, and negative at 3 years, when she was last seen at the venereal disease clinic.

Her physical measurements at the age of six were: weight, $30 \mathrm{lb}$; height, standing 40 inches, sitting 23 inches; circumference at nipple level 20 inches, at umbilicus 17 inches. The superficial and deep reflexes were present and equal. The liver was palpable below the costal margin on the left side but as the diaphragm is lower on that side this is not necessarily an accurate estimate of liver enlargement. Epigastric pulsation was apparent and the apex beat was visible. Palpation showed it to be three and a half inches from the mid-line and in the sixth left intercostal space. The beat was forceful and was felt over a wider area than usual. A rough systolic murmur was heard in this area, and posteriorly to the left of the vertebral column. Radiological examination showed a large cardiac shadow of abnormal contour and a subdiaphragmatic lateral heterotaxy (Fig. 3).

The electrocardiographic report was: "Normal sinus rhythm, rate 100 a minute. $P-R$ interval $0 \cdot 16$ second. The $P$ waves are upright in lead I, biphasic in lead II, inverted in lead III. There is left axis deviation with prominent $\mathrm{S}$ waves in leads I and II. From the unipolar limb leads the heart is in a horizontal position. V1 shows polyphasic initial deflection and late activation of the underlying ventricle. T waves inverted. V2 shows tiny $R$, small $S$, tall $R^{\prime}$ and moderate $S^{\prime}$ with inverted $T$ wave. In $V 3$ to $V 6 R$ and $S$ are approximately equal, with notching of the upstroke of $R$ in V3 to V5. T waves are upright in V3 to V5, sharply inverted in V6. Additional leads taken from the right of the chest resemble aVR with diminishing height of $R^{\prime}$ in V3R to V6R. The $T$ waves are inverted in V3R to V5R, upright in V6R. The cardiogram shows the heart to be in the left side of the chest. There is evidence, however, of right ventricular hypertrophy and the chest leads do not show any evidence of left ventricular activity." (Fig. 4.)

The parents in this case are believed to be normal, but they have not been radiologically examined. There is no history of congenital malformation in the family history of either parent.

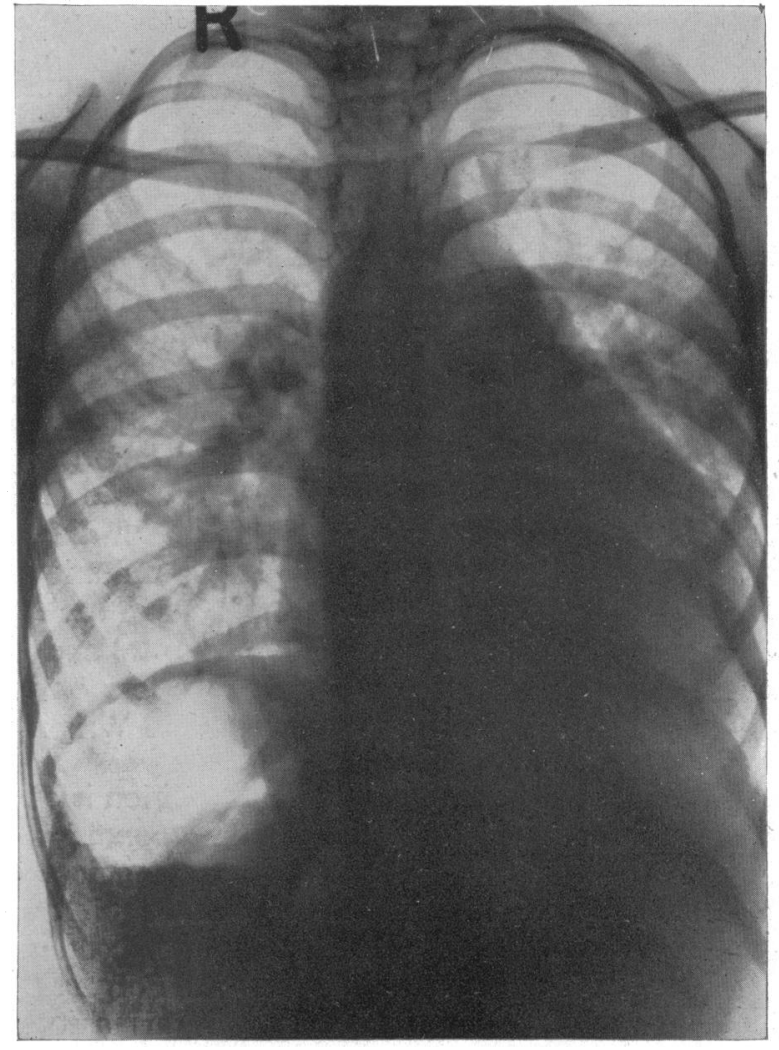

FIG. 3.-Case 2. Note the difference in the levels of the diaphragm on the two sides. 


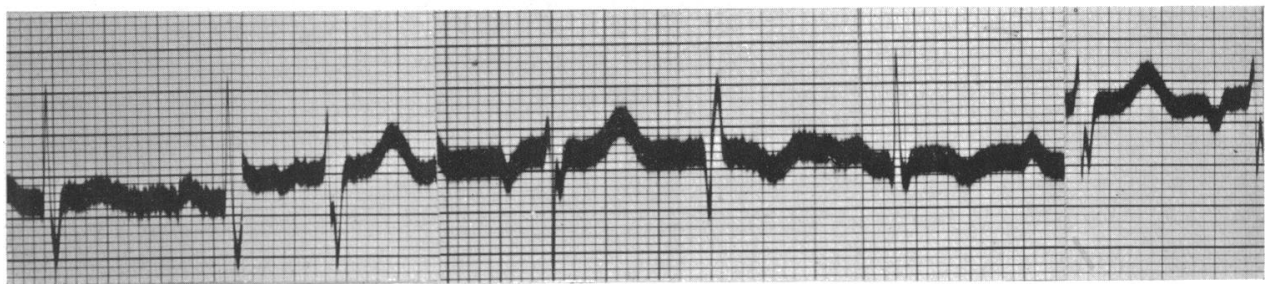

I

II

III

aVR

$\mathrm{aVL}$

$\mathrm{aVF}$

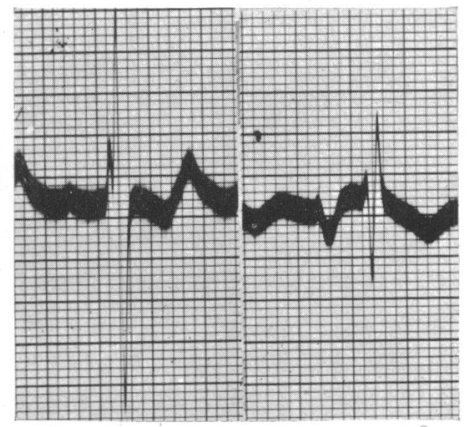

V3 $\quad$ V3R

Fig. 4.-Electrocardiogram from Case 2.

\section{Discussion}

In the course of an extensive survey of the literature on congenital dextrocardia, Lichtman (1931) made reference directly or indirectly to some cases. where the occurrence of congenital heart disease, with the heart in the sinister position, was associated with some degree of subdiaphragmatic lateral heterotaxy. He gave the following references: Breschet (1826), Geipel (1899), Hickman (1869), Hingst (1901), Knape (1912), Lochte (1898), Miller (1925), McCrae (1906), Royer and Wilson (1908), Shaw and Blake (1924). He mentioned the case described by Griffith (1899) but confused the reference of this case with Griffith (1897). Though he does not mention it, he appears to have been aware of Marchand's (1883) publication. He noted another case by hearsay.

To this total of twelve recorded cases Forgacs (1947) added two cases of his own recording. He gave an incorrect reference for Marchand (1883) stating that it is quoted by Gruber (1865). Hardy (1948) reported two cases and in a further search found four other records, one of which (Clemente, 1931) is not available for consultation in this country. To this total of twenty cases may be added two now reported, and one each recorded by Grossmann and Mellor (1928), by Grieshaber (1936) and probably by Gardière and Damez (1935). Taussig (1947) mentions having seen the condition three times, but describes only the post-mortem findings in a single case. A doubtful case described by Henderson and Wright (1927) should also be noted.

AEtiology. The ætiology of this condition is obscure, though it has been suggested by Cockayne (1928) that situs inversus is a hereditary condition carried by a recessive gene. It would thus be more obvious in the off-spring of consanguineous marriage. In neither of the two cases now recorded is there any question of consanguineous marriage, nor is there any family history of congenital abnormality on either line of descent.

In his appraisal of the recorded cases, Forgacs (1947) claimed that of fourteen cases eight showed a transposition of atria. Because of this association he developed the original suggestion of Lochte (1898) also referred to by Pernkopf (1926) and advanced the view that the transposition of the atria is the result of an hypertrophy of the left horn of the sinus venosus instead of the 
right horn, and that this in turn is caused by the transposition of the liver and ductus venosus which diverts most of the returning venous blood to the left horn instead of to the right as is usual.

This attractive theory does not rest on as good statistical evidence as Forgacs represented. From the eight cases that he claims as cases of transposition of the atria as many as four may be deducted. These are Miller (1925), McCrae (1906), Geipel, Case 3 (1899), and Forgacs (1947)*. Reference to Miller (1925) shows that no transposition of the atria was recorded. In the case of McCrae (1906) the heart was on the left but it was a mirror image heart of abnormal structure moved over to the sinister position. Transposition of the atria is recorded by Geipel, Case 3 (1899), but in this case the liver is on the right side. Forgacs' own case is omitted, for the diagnosis of transposition of the atria, though a good clinical one, is not supported by post-mortem evidence. If we limit our considerations to those cases that have come to autopsy, the theory is supported by four cases out of eleven.

Of the additional cases that have come to autopsy those reported by Taussig (1947) and by Pernkopf (1928) do appear to support the theory, but the case recorded by Hu (1929) is against it. Moreover, some cognizance must be taken of those cases of subdiaphragmatic lateral heterotaxy where it is claimed that the heart shows no abnormality. Geipel, Case 2 (1899), Goff (1927), Levrier (1932), and Buffé and Tanguy (1933) have each recorded one such case. Of these cases only that by Geipel had come to autopsy. It would appear that while the theory may have an application in the ætiology of some cases, where the condition arises in very early embryological life, its general application is not acceptable.

Diagnosis. In this syndrome the structural abnormality of the heart is usually a very prominent feature and is readily detected. This was so in the cases now recorded. So much is this so that a full clinical examination of the patient may not be made. Thus the accompanying subdiaphragmatic transposition of the viscera is overlooked. It is not without significance that the first ten cases to be recorded are spread over 87 years, from 1826 to 1912, while the next seventeen cases are reported in 37 years. Moreover, in British journals during 1947-49 three authors report two cases each. Thus the condition is probably not so uncommon as it seemed, and routine radiography in cases of congenital heart disease may result in more cases of this kind being recorded.

When it is observed clinically that the liver is transposed, it will be found that the lower edge of the liver is below the costal margin. In evaluating this sign it must be borne in mind that consequent upon cardiac development on the left side the level of the diaphragm on that side is lower than it is on the right side. Thus a normal sized but transposed liver will be at a lower level than one which is not transposed.

There are very few electrocardiographic records of this syndrome. Those which are published are confined to the standard leads, I, II, and III and a comparison of the recorded cases shows no uniform pattern. This is in keeping with the wide variety of abnormality in structure that has been found at autopsy in these cases. Because of the scanty information available it was felt desirable to record' a fuller cardiographic investigation in these two cases. The two records obtained show very different patterns. The record of Case 1 is almost unique in that a cardiographic record of dextrocardia was obtained from a case in which the heart is, on clinical examination, found in the sinister position and with the apex beat palpable on the left side. It is to be noted that in order to exclude the possibility of error this was repeated on a different occasion on the same apparatus and with the same result. Grieshaber (1936) recorded an inverted electrocardiogram in the case he reported--a girl, aged eight years. In the case recorded by Shaw and Blake (1924) a dextrocardia electrocardiogram was obtained, but it is very doubtful if this should be grouped with the others, for consideration of the radiological findings suggests that this is a dextrocardia with the heart in the mid-line position. A somewhat paradoxical situation is seen in the case recorded by Henderson and Wright (1927): this 15-year-old boy, who had a pigeon chest,

\footnotetext{
* Dr. Forgacs still thinks he is correct about Geipel, Case 3, and there is no question that the heart was on the left in McCrae's case, but Thompson's interpretation seems correct. Editor.
} 
was in an advanced state of congenital heart disease when he was seen by the authors. The left border of cardiac dullness was at the left nipple line and the right border at the right nipple line, while the greatest cardiac impulse was felt on the right side. Cardiac action was irregular and cardiographic examination showed this was probably due to fibrillation. A clinical diagnosis of dextrocardia was suggested but was not confirmed by the electrocardiogram.

Prognosis. The prognosis in this syndrome is undoubtedly the prognosis of the particular structural abnormality of the heart present in each case. This is well exemplified by the range of age which has been recorded. Grossmann and Mellor's patient was alive and 55 years old when reported, while in other cases, Marchand and Knape, the condition was not compatible with an independent existence for more than a few days.

\section{SUMMARY}

Two cases of subdiaphragmatic lateral heterotaxy associated with congenital heart disease, the heart being in the sinister position, are recorded. In one of these, however, an electrocardiogram indicative of dextrocardia has been obtained.

It is suggested that the condition is not so uncommon as the few reported cases would suggest.

The nature of the deviation from the normal will largely depend upon the stage of intrauterine development attained before the start of the abnormal development. The nature of the abnormality varies from case to case.

A list of the twenty-five reported cases is given.

The electrocardiograms in these two cases were made at the Royal Infirmary, Edinburgh, and it is a pleasure to acknowledge the report in Case 1, received from Dr. I. G. W. Hill, and in Case 2 from Dr. D. Haig.

\section{REFERENCES}

*Breschet, G. (1826). Rep. gen. d'anat. physiol. path. clin. chir., 2, 1.

Buffé, -., and Tanguy, -. (1933). Paris Méd., 2, 163.

*Clemente, G. (1931). Folia. Med., Napoli, 17, 347, 494, 521.

Cockayne, E. A. (1938). Quart. J. Med., 7, 479.

*Forgacs, P. (1947). Brit. Heart J., 9, 27.

*Gardière, C., and Damez (1935). Lyon Med., 156, 413.

* Geipel (1899). Quoted by Schelenz, 1909.

*Girod, R., and Sarasin, R. (1932). Schweiz. med. Wschr., 62, 1035.

Goff, Le (1927). Bull. Mem. Soc. Radiol. Mèd., France, 15, 331.

*Grieshaber, H. (1936). Schweiz. med. Wschr., 66, 1307.

Griffith, W. (1897). Brit. med. J., 1, 1287.

*Griffith, J. P. C. (1899). Univ. med. Gaz., 7, 666.

*Grossmann, J., and Mellor, O. (1928). Fortschr. Geb. Rontgenstrahlee, 38, 1120.

Gruber, W. (1865). Arch. Anat. Physiol., Reichert, C. B. u. Du Bois-Reymond, E., Leipzig, 558.

*Hardy, R. H. (1948). Arch. Dis. Childh., 23, 137.

*Henderson, J., and Wright, J. (1927). Glasg. med. surg. J., 108, 353.

*Hickman, W. (1869). Trans. Path. Soc., Lond., 20, 88.

*Hingst, (1901). Dissert. Keil. Quoted by Schelenz, 1909.

*Hu, G. H. (1929). Amer. J. Path., 5, 389.

*Knape, W. (1912). Virchow's Arch., 209, 473.

Levrier, H. (1932). Bull. Mem. Soc. Radiol. Med., France, 22, 469.

Lichtman, S. S. (1931). Arch. intern. Med., 48, 683.

*Lochte (1898). Beitrag. path. Anat. allg. Path., 24, 187.

*Marchand, F. (1883). Ber. Arb. Gebürtshulflichgynäk. Klinik zu Giessen. 1881-82. (Ahlfeld. F.) mit Beit. von Marchand, F. Leipzig, 254.

*Miller, A. J. (1925). Amer. J. Path., 1, 467.

* McCrae, J. (1906). J. Anat. Physiol., 40, 28.

Pernkopf, E. (1926). Anat. Entwick Gesch., 79, 577.

*- (1928). Ibid., 87, 661 .

*Royer, B. F., and Wilson, J. D. (1908). Arch. Ped., 25, 881. (1908). Brit. Dis. Child., 5, 176.

Schelenz, C. (1909). Berl. Klin. Wschr., 46, 788.

*Shaw, E., and Blake, H. K. (1924). Amer. J. Dis. Child., 28, 204.

*Taussig, H. B. (1947). Congenital Malformations of the Heart, New York, p. 513. 